\title{
Utilisation des protéines du lait et du lactosérum par le jeune veau préruminant. Influence de l'âge et de la dénaturation des protéines du lactosérum
}

\author{
J.-F. GRONGNET, P. PATUREAU-MIRAND *, \\ R. TOULLEC et J. PRUGNAUD *
}

avec la collaboration technique de J.N. NoucheT, J. LAREYNIE, M. Lesage, Marie-Claude ValluY* et O. Bernard*

I.N.R.A., Station de Recherches zootechniques, 65, rue de Saint-Brieuc, F 35042 Rennes Cedex I.N.R.A., * Laboratoire d'Etudes du Métabolisme Azoté, Theix, F 63710 Beaumont

\section{Résumé}

Trois aliments d'allaitement (Témoin, RD et RN) sont préparés. Dans l'aliment Témoin, les protéines sont fournies en totalité par de la poudre de lait écrémé supplémentée en méthionine; dans les aliments RD et RN, 58 p. 100 des protéines sont apportées par un rétentat de lactosérum dénaturé (RD) ou natif $(\mathrm{RN})$, le reste provenant de la poudre de lait écrémé. Les 2 rétentats sont pasteurisés $\left(72^{\circ} \mathrm{C}\right.$, quelques secondes), puis concentrés et séchés par atomisation. La dénaturation du produit RD est effectuée par un chauffage supplémentaire $\left(75^{\circ} \mathrm{C}, 30 \mathrm{mn}\right)$ appliqué après la concentration; le pourcentage de protéines dénaturées passe ainsi de 8 à 34 .

Chacun des aliments est distribué à 5 veaux mâles Holstein $x$ Frisons à partir de l'âge d'un jour. La digestibilité est mesurée de 3 à $8\left(\mathrm{P}_{1}\right)$, de 14 à $19\left(\mathrm{P}_{2}\right)$ et de 28 à $33 \mathrm{j}\left(\mathbf{P}_{3}\right)$. La digestibilité apparente de l'aliment Témoin augmente régulièrement de la $P_{1}$ à la $\mathrm{P}_{:}$, passant ainsi pour l'azote de $0,87 \mathrm{l}$ à 0,935 et 0,966 . Celle des 2 autres aliments n'augmente qu'entre la $P_{::}$et la $P_{: 3}$, évoluant ainsi pour l'azote de 0,888 à 0,896 et 0,950 (RD) et de 0,859 à 0,854 et 0,923 (RN). Les variations individuelles sont plus importantes

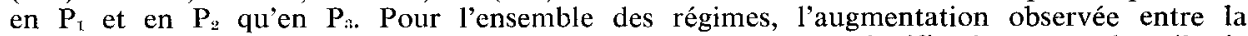
$P_{2}$ et la $P_{3}$ est significative. La digestibilité de l'azote est significativement plus élevée avec l'aliment Témoin qu'avec l'aliment $R N$ en $P_{3}$.

L'examen de la composition en acides aminés des fèces indique que l'augmentation de la digestibilité apparente de l'azote avec l'âge correspond vraisemblablement à une amélioration de la digestion des protéines alimentaires et endogènes. Il en serait de même en $\mathbf{P}_{1}$ pour expliquer les digestibilités individuelles plus élevées observées chez certains veaux. La digestibilité réelle des protéines des aliments RD et surtout RN semble moins élevée que celle des protéines du lait. Les teneurs en acides aminés libres du sang, notamment en lysine, sont peu influencées par la dénaturation.

L'utilisation digestive des protéines du lait et du lactosérum augmente de la naissance à la cinquième semaine d'âge. Les protéines du lactosérum sont un peu moins bien utilisées que celles du lait durant cette période, mais leur dénaturation partielle par voie thermique permet d'en améliorer la digestibilité réelle. Les traitements thermiques modérés peuvent donc accroître la valeur nutritionnelle de certains produits laitiers. 


\section{1. - Introduction}

Chez le veau préruminant, la digestibilité des protéines augmente au cours des 4 ou 5 premières semaines qui suivent la naissance (Nishimatsu \& Kumeno, 1966 ; Bouchard, Brisson \& Julien, 1973 ; Bell, Royan \& Youngs, 1974; Toullec, Frantzen \& Mathieu, 1974 ; Stobo \& Roy, 1977). Cette augmentation est généralement plus importante pour les protéines de substitution que pour celles du lait. Elle est notamment liée à un accroissement des quantités d'acide chlorhydrique et d'enzymes protéolytiques pancréatiques sécrétés durant cette période (Huber et al., 1961 ; TERNOUTH \& ROY, 1973).

Les protéines du lactosérum sont probablement les protéines de substitution les mieux utilisées par le veau, que ce soit au niveau digestif (Toullec et al., 1969 ; Toullec, Mathieu \& Pion, 1974 ; Toullec et al., 1974) ou pour la croissance (Stewart, Muller \& Griffin, 1974; Toullec, Mathieu \& Pion, 1974). Leur sensibilité à l'hydrolyse enzymatique est cependant moindre que celles des caséines, mais elle peut être accrue par un traitement thermique dénaturant (Tourneur \& Lenolr, 1980). Le but de cet essai était de décrire, chez le jeune veau préruminant, l'évolution avec l'âge de l'utilisation digestive (digestibilité, composition en acides aminés des fèces) et métabolique (rétention de l'azote, du calcium et du phosphore, amino-acidémie) des protéines entières du lait et de la comparer à celle des protéines du lactosérum natives ou dénaturées par la chaleur.

\section{2. - Matériel et méthodes}

\section{Aliments}

Un lactosérum de fromage à pâte pressée a été traité par ultrafiltration, de manière à obtenir 2 rétentats (natif : $\mathrm{RN}$, ou dénaturé : RD) contenant environ 37 p. 100 de protéines par rapport à la matière sèche (tabl. 1). Les rétentats ont été pasteurisés ( $72^{\circ} \mathrm{C}$, quelques secondes) puis concentrés et séchés par atomisation. Les protéines du rétentat RD ont été partiellement dénaturées par un chauffage supplémentaire $\left(75^{\circ} \mathrm{C}, 30 \mathrm{mn}\right)$, appliqué après la concentration; le pourcentage de protéines dénaturées, déterminé d'après la solubilité à $\mathrm{pH} 4,6$ est ainsi passé de 8 (RN) à 34 (RD). En revanche, la composition en acides aminés n'a pas été sensiblement modifiée (tabl. 2).

Trois aliments d'allaitement, dont la matière sèche contenait environ 26 p. 100 de protéines, ont été préparés (tabl. 3). Dans l'aliment Témoin, les protéines étaient fournies en totalité par de la poudre de lait écrémé supplémentée par de la méthionine de synthèse. Dans les aliments RD et RN, 58 p. 100 des protéines étaient apportées par le rétentat, dénaturé ou natif, et le reste par de la poudre de lait écrémé.

\section{Animaux et mesures}

Quinze veaux mâles Holstein x Frisons, issus du troupeau de vaches laitières de l'Ecole Nationale Supérieure Agronomique de Rennes, ont été utilisés. Les veaux 


\section{TABLEAU 1}

Composition des rétentats (p. 100 de la matière sèche) Composition of whey protein concentrates ( $p .100$ of dry matter)

\begin{tabular}{|c|c|c|}
\hline $\begin{array}{c}\text { Rétentat } \\
\text { Whey protein concentrate }\end{array}$ & $\begin{array}{l}\text { Dénaturé } \\
\text { Denaturated }\end{array}$ & $\begin{array}{l}\text { Natif } \\
\text { Native }\end{array}$ \\
\hline $\begin{array}{l}\text { Matières azotées }(\mathrm{N} \times 6,25) \ldots \ldots \ldots \\
\text { Crude protein }\end{array}$ & 37,2 & 37,1 \\
\hline $\begin{array}{l}\text { Matières grasses } \ldots \ldots \ldots \ldots \ldots \ldots \ldots \ldots \ldots \ldots \ldots \\
F_{a t}\end{array}$ & 2,2 & 2,2 \\
\hline $\begin{array}{l}\text { Cendres } \\
\text { Ash }\end{array}$ & 5,9 & 5,8 \\
\hline $\mathrm{Ca}$ & 0,46 & 0,51 \\
\hline 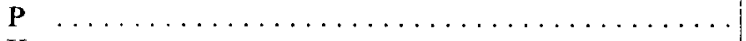 & 0,50 & 0,52 \\
\hline 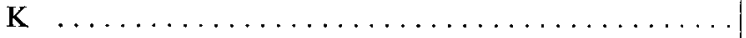 & 1,72 & 1,78 \\
\hline 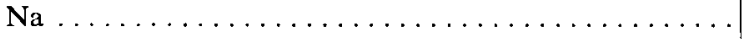 & 0,58 & 0,53 \\
\hline 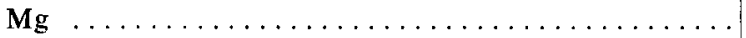 & 0,11 & 0,12 \\
\hline 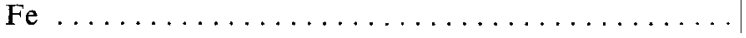 & 0,0012 & 0,0014 \\
\hline
\end{tabular}

Tableau 2

Composition en acides aminés des rétentats et des aliments $(\mathrm{g} / 16 \mathrm{~g} \mathrm{~N})$ Amino-acid composition of whey protein concentrates and of diets $(g / 16 \quad g \quad N)$

\begin{tabular}{|c|c|c|c|c|c|}
\hline \multirow{2}{*}{$\begin{array}{l}\text { Produit } \\
\text { Product }\end{array}$} & \multicolumn{2}{|c|}{$\begin{array}{l}\text { Rétentat - Whey } \\
\text { protein concentrate }\end{array}$} & \multicolumn{3}{|c|}{ Aliment - Diet } \\
\hline & $\mathrm{RD}(1)$ & RN (2) & $\begin{array}{l}\text { Témoin } \\
\text { Control }\end{array}$ & $\mathrm{RD}(1)$ & RN (2) \\
\hline A. aspartique $\ldots \ldots \ldots \ldots$ & 10,95 & 10,60 & 7,85 & 9,80 & 9,60 \\
\hline Thréonine & 6,90 & 6,65 & 4,25 & 5,80 & 5,65 \\
\hline Sérine & 5,65 & 5,70 & 5,65 & 5,75 & 5,80 \\
\hline A. glutamique $\ldots \ldots \ldots$ & 18,05 & 16,35 & 20,40 & 19,15 & 18,20 \\
\hline Proline $\ldots .$. & 7,80 & 7,70 & 11,30 & 9,30 & 9,25 \\
\hline Glycine $\ldots \ldots \ldots \ldots \ldots \ldots$ & 2,30 & 2,10 & 1,90 & 2,15 & 2,05 \\
\hline Alanine $\ldots \ldots \ldots \ldots \ldots$ & 5,30 & 5,35 & 3,50 & 4,55 & 4,60 \\
\hline Valine $\ldots \ldots \ldots \ldots \ldots \ldots$ & 5,95 & 5,35 & 5,75 & 6,05 & 5,70 \\
\hline Cystine ... & 3,00 & 2,85 & 1,05 & 2,25 & 2,15 \\
\hline Methionine & 1,85 & 1,95 & 3,80 & 2,40 & 2,45 \\
\hline$\ldots \ldots \ldots \ldots$ & 6,25 & 5,70 & 4,85 & 5,80 & 5,45 \\
\hline Leucine . . & 10,40 & 9,10 & 9,25 & 9,95 & 9,20 \\
\hline Tyrosine $\ldots \ldots \ldots \ldots \ldots$ & 3,00 & 2,95 & 4,80 & 3,90 & 3,85 \\
\hline Phénylalanine $\ldots \ldots \ldots \ldots$ & 3,25 & 3,25 & 4,70 & 3,95 & 3,95 \\
\hline Lysine $\ldots \ldots \ldots \ldots \ldots$ & 8,65 & 8,70 & 7,25 & 8,05 & 8,05 \\
\hline Histidine...$\ldots \ldots \ldots$ & 2,15 & 2,05 & 2,80 & 2,40 & 2,35 \\
\hline Arginine & 2,50 & 2,15 & 3,20 & 2,80 & 2,60 \\
\hline $\begin{array}{l}\text { (1) Dénaturé - Denaturated. } \\
\text { (2) Natif - Native. }\end{array}$ & & & & & \\
\hline
\end{tabular}




\section{TABLEAU 3}

Composition des aliments

Composition of the diets

\begin{tabular}{|c|c|c|c|}
\hline $\begin{array}{l}\text { Aliment } \\
\text { Diet }\end{array}$ & $\begin{array}{l}\text { Témoin } \\
\text { Control }\end{array}$ & RD & RN \\
\hline $\begin{array}{l}\text { CONSTITUANTS }(\% \text { de l'aliment }) \ldots \ldots \ldots \ldots \ldots \ldots \\
\text { COMPONENTS }(\% \text { of the diet }) \\
\text { Poudre de lait écrémé } \ldots \ldots \ldots \ldots \ldots \ldots \ldots \ldots \ldots \ldots\end{array}$ & & & \\
\hline $\begin{array}{l}\text { Skim milk powder } \\
\text { Rétentat de lactosérum } \ldots \ldots \ldots \ldots \ldots \ldots \ldots \ldots \ldots \ldots \\
\text { Whey protein concentrate }\end{array}$ & 70,8 & 30,0 & 30,0 \\
\hline 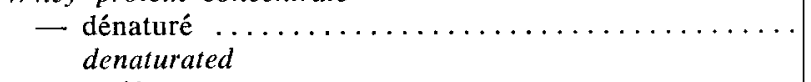 & - & 40,55 & - \\
\hline 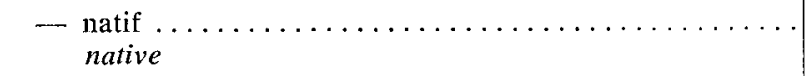 & - & - & 40,55 \\
\hline $\begin{array}{l}\text { Suif }(1) \ldots \ldots \ldots \ldots \ldots \ldots \ldots \ldots \ldots \ldots \ldots \ldots \ldots \ldots \ldots \ldots \ldots \\
\text { Tallow: }\end{array}$ & 8,6 & 8,4 & 8,4 \\
\hline $\begin{array}{l}\text { Huile de coprah (1) } \ldots \ldots \ldots \ldots \ldots \ldots \ldots \ldots \ldots \ldots \ldots \ldots \\
\text { Coconut oil }\end{array}$ & 8,6 & 8,4 & 8,4 \\
\hline $\begin{array}{l}\text { Monoglycérides de suif (1) } \ldots \ldots \ldots \ldots \ldots \ldots \ldots \ldots \ldots \\
\text { Tallow monoglycerides }\end{array}$ & 0,4 & 0,4 & 0,4 \\
\hline $\begin{array}{l}\text { Lactose } \\
\text { Lactose }\end{array}$ & 7,6 & 7,1 & 7,1 \\
\hline $\begin{array}{l}\text { Amidon prégélatinisé } \ldots \ldots \ldots \ldots \ldots \ldots \ldots \ldots \ldots \ldots \ldots \ldots \ldots \ldots \\
\text { Pregelatinized starch }\end{array}$ & 2,0 & 2,0 & 2,0 \\
\hline $\begin{array}{l}\text { Dl méthionine } \\
\text { Dl methionine }\end{array}$ & 0,23 & - & - \\
\hline 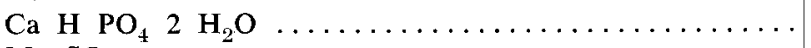 & 1,00 & 2,29 & 2,29 \\
\hline 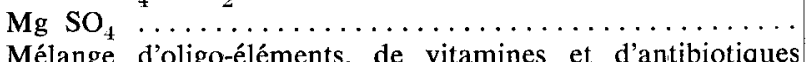 & 0,32 & 0,45 & 0,45 \\
\hline 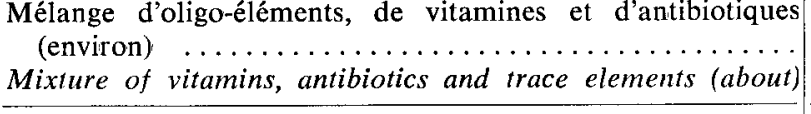 & 0,4 & 0,4 & 0,4 \\
\hline $\begin{array}{l}\text { COMPOSITION CHIMIQUE (\% de M.S.) } \\
\text { CHEMICAL COMPOSITION (\% of D.M.) }\end{array}$ & & & \\
\hline $\begin{array}{l}\text { Matières azotées }(\mathrm{N} \times 6,25) \ldots \ldots \ldots \ldots \ldots \ldots \ldots \ldots \ldots \ldots \ldots \\
\text { Crude protein }\end{array}$ & 26,5 & 26,2 & 26,2 \\
\hline $\begin{array}{l}\text { Matières grasses } \ldots \ldots \ldots \ldots \ldots \ldots \ldots \ldots \ldots \\
\text { Fat }\end{array}$ & 18,1 & 17,9 & 17,9 \\
\hline $\begin{array}{l}\text { Matières minérales } \ldots \ldots \ldots \\
\text { Ash }\end{array}$ & 6,9 & 7,0 & 6,9 \\
\hline $\mathrm{Ca} \ldots$ & 1,29 & 1,15 & 1,17 \\
\hline P. & 0,91 & 0,86 & 0,86 \\
\hline K & 1,21 & 1,19 & 1,22 \\
\hline $\mathrm{Na}$ & 0,36 & 0,38 & 0,36 \\
\hline $\mathrm{Mg} .$. & 0,16 & 0,21 & 0,22 \\
\hline$\cdots$ & 0,0018 & 0,0023 & 0,0024 \\
\hline
\end{tabular}

(1) Les matières grasses ont été incorporées dans du lait écrémé concentré, à raison de $35 \mathrm{p}$. 100 de la matière sèche; le mélange ainsi obtenu a été homogénéisé et séché selon le procédé Spray.

The fats were incorporated into concentrated skim milk at the rate of $35 \%$ of DM; the mixture was then homogenized and spray-dried. 
nés avant $15 \mathrm{~h}$ ont reçu 2 repas de colostrum $(1,5$ et $2 \mathrm{~kg})$ le jour de leur naissance ; ceux nés après $15 \mathrm{~h}$ ont reçu 1 repas de colostrum $(1,5 \mathrm{~kg})$ le jour de leur naissance et 2 repas $(2 \times 2 \mathrm{~kg})$ le lendemain. Le matin du jour qui a suivi la distribution du dernier repas de colostrum, les veaux ont été affectés à l'un des régimes alimentaires (Témoin, RD ou RN).

La première période de récolte des fèces et des urines a commencé $48 \mathrm{~h}$ plus tard et a duré 5 jours consécutifs. Deux autres périodes, de même longueur, ont commencé respectivement du quinzième jour d'âge et le dimanche le plus proche du vingt-huitième jour. Les animaux ont été pesés au début et à la fín de chaque période. Ils ont été alimentés au seau 2 fois par jour; les quantités distribuées ont augmenté avec l'âge, passant de $43 \mathrm{~g}$ de matière sèche $/ \mathrm{kg}$ de poids vif $0,75 / \mathrm{j}$ en première période, à 48 jusqu'à la fin de la seconde et à 53 ensuite.

Des prélèvements de sang ont été effectués dans la veine jugulaire à la fin des 2 premières périodes, $4 \mathrm{~h}$ à $4 \mathrm{~h} 30$ après le repas du matin; ils ont servi à mesurer les teneurs en acides aminés libres, sur des échantillons moyens obtenus en mélangeant les sangs des 5 animaux recevant le même traitement (Patureau-Mirand et al., 1974). Les méthodes d'échantillonnage et d'analyse des aliments, des fèces, et des urines, ont été rapportées précédemment (Paruelle et al., 1972 ; Paruelle, Toullec \& Mathieu, 1973 ; Patureau-Mirand et al., 1974 ; Prugnaud \& Pion, 1976). Les résultats des bilans ont été soumis à une analyse de variance et les moyennes ont été classées selon le test de Newman \& Keuls (Snedecor \& Cochran, 1971). Les compositions en acides aminés des fèces ont été comparées entre elles et à celles de protéines alimentaires, endogènes ou bactériennes en calculant la distance du $\chi^{2}$ (Gullloteau et al., 1980). Les protéines de méconium de veau (Patureau-Mirand, résultats non publiés) ont été utilisées pour représenter les protéines endogènes non digérées. Les protéines des bactéries isolées de fèces de porc (MASON, Just \& BeCHANDERSEN, 1976) ont été choisies pour représenter les protéines microbiennes.

\section{3. - Résultats}

\section{Etat sanitaire, appétit et croissance}

Deux veaux sont décédés, dont l'un accidentellement dans le lot Témoin et l'autre à la suite d'une diarrhée dans le lot RD; ces animaux ont été remplacés. La fréquence des jours de diarrhée a été peu importante (tabl. 4). Elle a été la plus élevée chez les veaux du lot RN et la plus faible chez ceux du lot RD. Elle a été plus élevée en périodes 1 et 2 qu'en période 3 .

L'appétit des animaux a été très satisfaisant dans tous les lots (respectivement $0,1-0,9$ et 1 p. 100 de refus avec les aliments Témoin, RD et RN, de la naissance à $33 \mathrm{j}$ ). Le gain de poids vif et l'indice de consommation ont été meilleurs avec l'aliment Témoin $(736 \mathrm{~g} / \mathrm{j}$ et $1,20 \mathrm{~kg}$ de matière sèche $/ \mathrm{kg}$ de gain de poids vif) qu'avec les aliments RD (691 et 1,23$)$ et surtout RN (626 et 1,40); cependant, aucune de ces différences n'a été significative. 


\section{Tableau 4}

Etat des fèces (p. 100 du nombre de jours de récolte)

Classification of faeces ( $p .100$ of number of sampling days)

\begin{tabular}{|c|c|c|c|}
\hline $\begin{array}{c}\text { Etat (1) } \\
\text { Classification }\end{array}$ & $\begin{array}{l}\text { Diarrhéique } \\
\text { Diarrhoeic }\end{array}$ & $\begin{array}{l}\text { Relâché } \\
\text { Loose }\end{array}$ & $\begin{array}{l}\text { Normal } \\
\text { Normal }\end{array}$ \\
\hline $\begin{array}{l}\text { Teneur en matière sèche }(\%) \\
\text { Dry matter content }(\%)\end{array}$ & $\mathrm{MS} \leqslant 12$ & $20 \geqslant \mathrm{MS}>12$ & $\mathrm{MS}>20$ \\
\hline \multicolumn{4}{|l|}{$\begin{array}{l}\text { Aliment } \\
\text { Diet }\end{array}$} \\
\hline $\begin{array}{l}\text { - Témoin } \\
\text { Control }\end{array}$ & 5,6 & 35,7 & 57,2 \\
\hline 一 R.D. . & 4,2 & 44,9 & 50,9 \\
\hline - R.N. .. & 8,3 & 45,8 & 45,8 \\
\hline \multicolumn{4}{|l|}{$\begin{array}{l}\text { Période (âge en } \mathbf{j}) \\
\text { Periode (age, } d \text { ) }\end{array}$} \\
\hline$-1(3,3$ à 8,3$)$ & 9,8 & 35,1 & 55,1 \\
\hline$-2(14,1-19,0)$ & 7,0 & 32,3 & 60,7 \\
\hline$-3(28,0-33,0)$ & 1,4 & 60,4 & 38,2 \\
\hline $\begin{array}{l}\text { (1) Selon la classification } \\
\text { According to the class }\end{array}$ & $\begin{array}{l}\text { XTER et } \\
\text { TER and }\end{array}$ & $\begin{array}{l}(1953) \text {. } \\
(1953) \text {. }\end{array}$ & \\
\hline
\end{tabular}

\section{- Digestibilité}

Utilisation digestive des aliments

La digestibilité apparente des constituants de l'aliment Témoin, calcium excepté, augmente régulièrement de la première à la troisième période, passant ainsi pour l'azote de 0,871 à 0,935 et 0,966 (fig. 1 et 2). Pour les 2 autres aliments, la digestibilité n'augmente qu'entre la seconde et la troisième période. Globalement, l'effet de l'âge est significatif pour la matière sèche, la matière organique, l'azote (période $3>$ périodes 1 et 2 ) et l'extractif non azoté (période $3>$ période 2 ).

Aucune différence significative n'est observée entre les régimes au cours des 2 premières périodes (fig. 1 et 2 ). En revanche, pendant la troisième période, la digestibilité de la matière sèche et celle de la matière organique sont significativement plus élevées avec les aliments Témoin et RD qu'avec l'aliment RN ; celles de l'azote, du calcium et du phosphore sont significativement plus élevées avec l'aliment Témoin qu'avec l'aliment RN. 


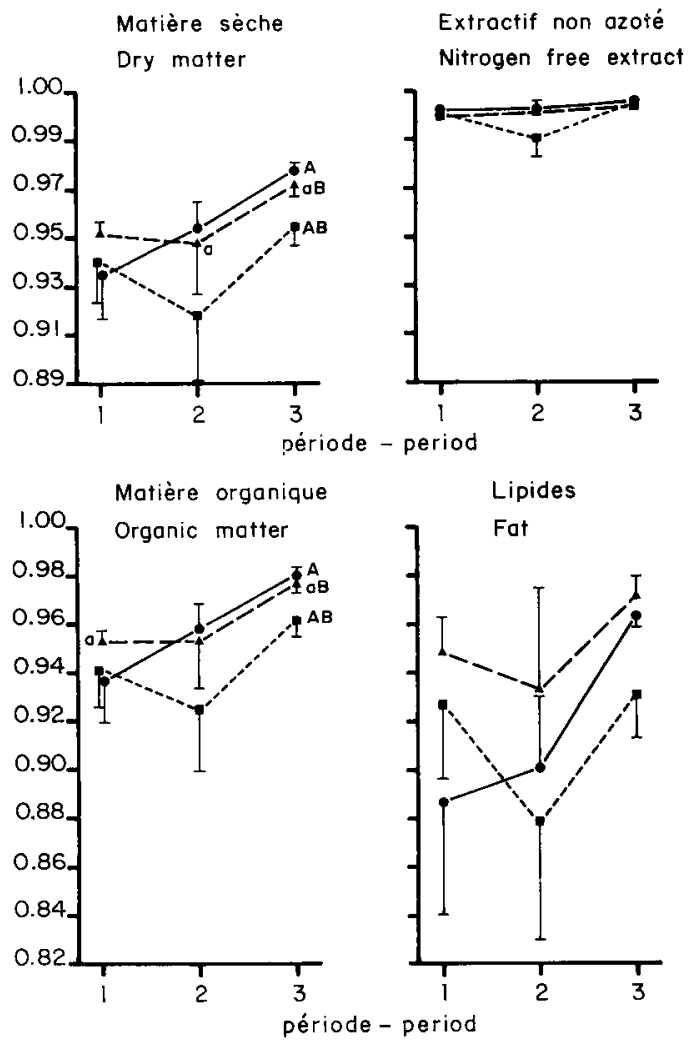

FIG. 1

Evolution avec l'âge de la digestibilité apparente de la matière sèche, de la matière organique, de l'extractif non azoté et des lipides (moyennes et écarts-types des moyennes)

$V$ ariation with age in the apparent digestibility of dry matter, organic matter, nitrogen free extract and fat (means and standard errors)

- Aliment Témoin - Control diet.

$\Delta \ldots \Delta$ Aliment RD - RD diet.

-..- Aliment RN - RN diet.

Signffication statistique - Statistical significance $(p<0.05)$.

— $\mathrm{a}, \mathrm{b}$ : différence significative entre périodes accompagnées de la même lettre significant difference between periods carrying the same letter.

- A, B : différence significative entre aliments accompagnés de la même lettre significant difference between diets carrying the same letter.

Pour l'ensemble de l'essai - For the whole trial :

- l'effet «protéines» et l'interaction ne sont pas significatifs - protein effect and interaction are not significant;

- l'effet «âge » est significatif pour la matière sèche et pour la matière organique $\left(\mathrm{P}_{1}\right.$ et $\left.\mathrm{P}_{2}<\mathrm{P}_{i}\right)$, ainsi que pour l'extractif non azoté $\left(\mathrm{P}_{2}<\mathrm{P}_{3}\right)$ - age effect is significant for $D M$ and $O M\left(P_{1}\right.$ and $\left.P_{2}<P_{3}\right)$, and for nitrogen free extract $\left(P_{2}<P_{s}\right)$. 

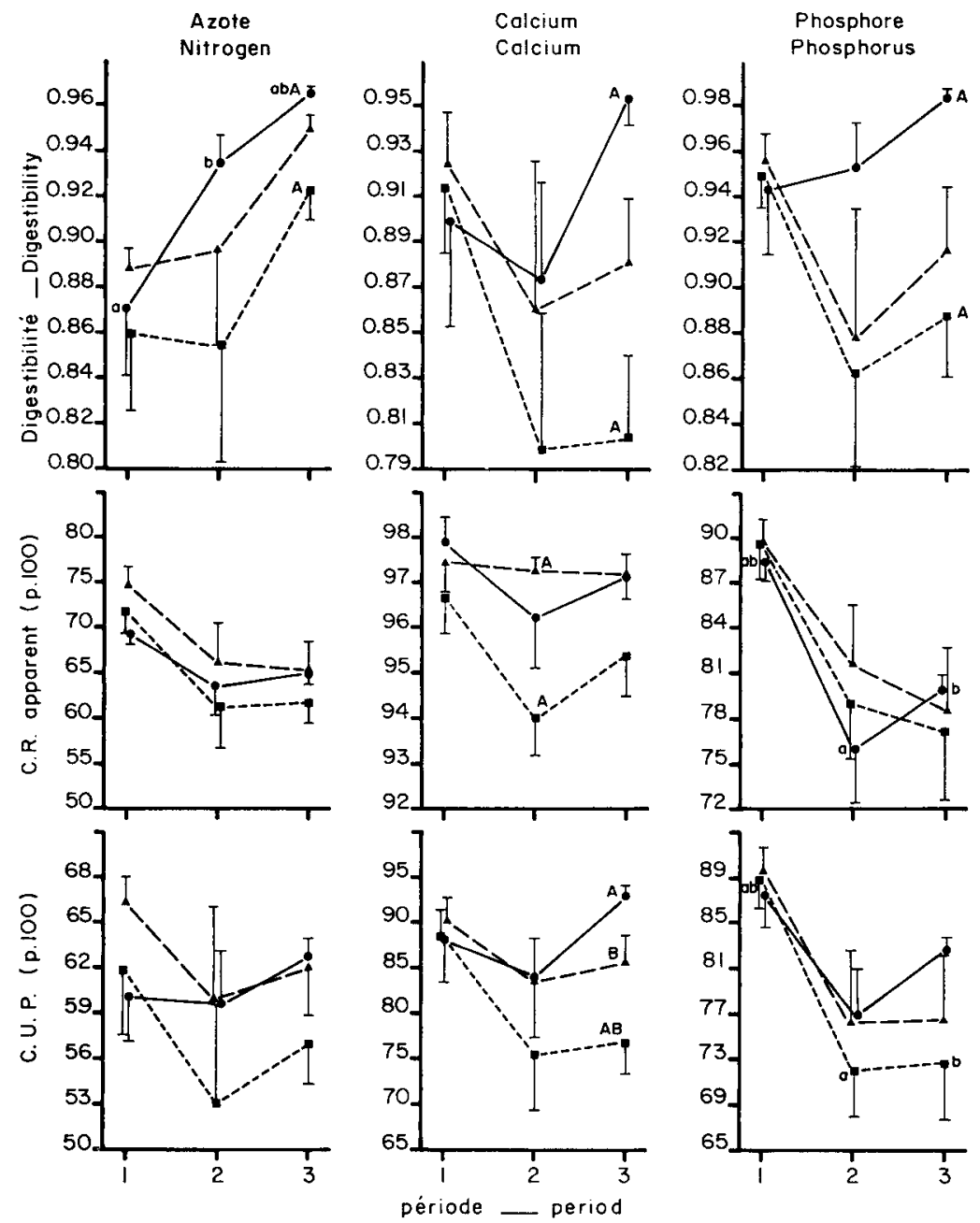

Fig. 2

Evolution avec l'âge de la digestibilité apparente, du coefficient de rétention apparente (C.R.) et du coefficient d'utilisation pratique (C.U.P.) de l'azote, du calcium et du phosphore (moyennes et écarts-types des moyennes)

Variation with age in the apparent digestibility, of C.R. and C.U.P. of nitrogen, calcium and phosphorus (means and standard errors)

$$
\begin{aligned}
& \text { C.R. }=\frac{\text { Ingéré }-(\text { fécal }+ \text { urinaire })}{\text { Ingéré }- \text { fécal }} \times 100=\frac{\text { lntake }-(\text { faecal }+ \text { urinary })}{\text { Intake }- \text { faecal }} \times 100 \\
& \text { C.U.P. }=\frac{\text { Ingéré }-(\text { fécal }+ \text { urinaire })}{\text { ingéré }} \times 100=\frac{\text { Intake }-(\text { faecal }+ \text { urinary })}{\text { Intake }} \times 100
\end{aligned}
$$




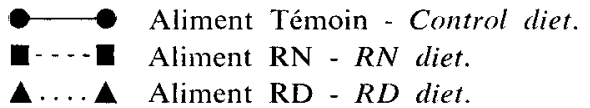

Signification statistique - Statistical significance $(p<0.05)$.

— a, b : différence significative entre périodes accompagnées de la même lettre significant difference between periods carrying the same letter.

- A, B : différence significative entre aliments accompagnés de la même lettre significant difference between diets carrying the same letter.

Pour l'ensemble de l'essai - For the whole trial :

- l'effet «protéines» est signilicatif pour la digestibilité du $\mathbf{P}$ (aliment Témoin $>$ aliment $\mathrm{RN}$ ) et le C.R. du Ca (aliments Témoin et $\mathrm{RD}>$ aliment $\mathrm{RN}$ ) - nrotein effect is significant for $P$ digestibility (Control $>R N$ ) and Ca C.R. (Control and $R D>R N$ );

- l'effet «âge» est significatif pour la digestibilité de l'azote $\left(\mathbf{P}_{1}\right.$ et $\mathrm{P}_{2}<\mathbf{P}_{3}$ ) ainsi que le C.R. de l'azote et du $\mathbf{P}$ et le C.U.P. du $\mathbf{P}\left(\mathbf{P}_{1}>\mathbf{P}_{2}\right.$ et $\left.\mathbf{P}_{3}\right)$ - age effect is significant for $N$ digestibility $\left(P_{1}\right.$ and $\left.P_{z}<P_{s}\right)$, for $N$ and $P$ C.R. and for P C.U.P. $\left(P_{1}>P_{2}\right.$ and $P_{s}$ );

- l'interaction n'est significative que pour le C.U.P. du P - interaction is significant only for P C.U.P.

\section{- Composition en acides aminés des fèces}

Les variations individuelles observées dans la digestibilité de l'azote sont beaucoup plus fortes en première qu'en troisième période, avec les aliments Témoin et surtout RN (fig. 2). En conséquence, les fèces de la première période sont regroupées différemment avant l'analyse (tabl. 5). Celles des animaux du lot Témoin sont réparties en 2 groupes de 3 et 2 correspondant respectivement aux digestibilités les plus faibles et les plus fortes. Celles des animaux du lot $\mathrm{RN}$ sont réparties en 3 groupes de 1,1 et 3, correspondant respectivement aux digestibilités faible, moyenne et forte. Enfin, un seul groupe est constitué avec les fèces des veaux du lot RD en première période, de même quavec les fèces des animaux de chaque lot en troisième période.

La composition en acides aminés des fèces varie dans des limites relativement étroites (tabl. 5) puisque les distances du $\chi^{2}$ entre fèces sont comprises entre 6 et 53 (tabl. 6). Il est cependant possible de décrire quelques tendances selon la digestibilité de l'azote et l'âge des animaux, ainsi que l'origine et le traitement des protéines alimentaires. En période 1, quand la digestibilité de l'azote des aliments Témoin et RN augmente, les teneurs en thréonine et en sérine s'accroissent et celles en leucine, isoleucine, phénylalanine et lysine diminuent. Quand l'âge augmente, quel que soit le régime, la part de l'azote des acides aminés dans l'azote total et les teneurs en thréonine, sérine et proline baissent, tandis que celles en acide glutamique, glycine, valine, alanine et méthionine s'accroissent (tabl. 5). Par rapport aux fèces des veaux recevant l'aliment Témoin, celles des veaux qui consomment les aliments RD et RN sont plus riches en lysine et moins pourvues en arginine. Les teneurs en thréonine et en sérine des fèces sont plus élevées en période 3 avec l'aliment RN qu'avec l'aliment $\mathrm{RD}$, tandis que la teneur en tyrosine est plus faible au cours des 2 périodes analysées.

Par rapport aux fèces de la période 3 , celles de la période 1 ont une composition en acides aminés plus proche de celle du méconium ( $\chi^{2}$ variant de 67 à 126 au lieu de 123 à 159) et plus éloignée de celle des bactéries fécales ( $\chi^{2}$ variant de 69 à 


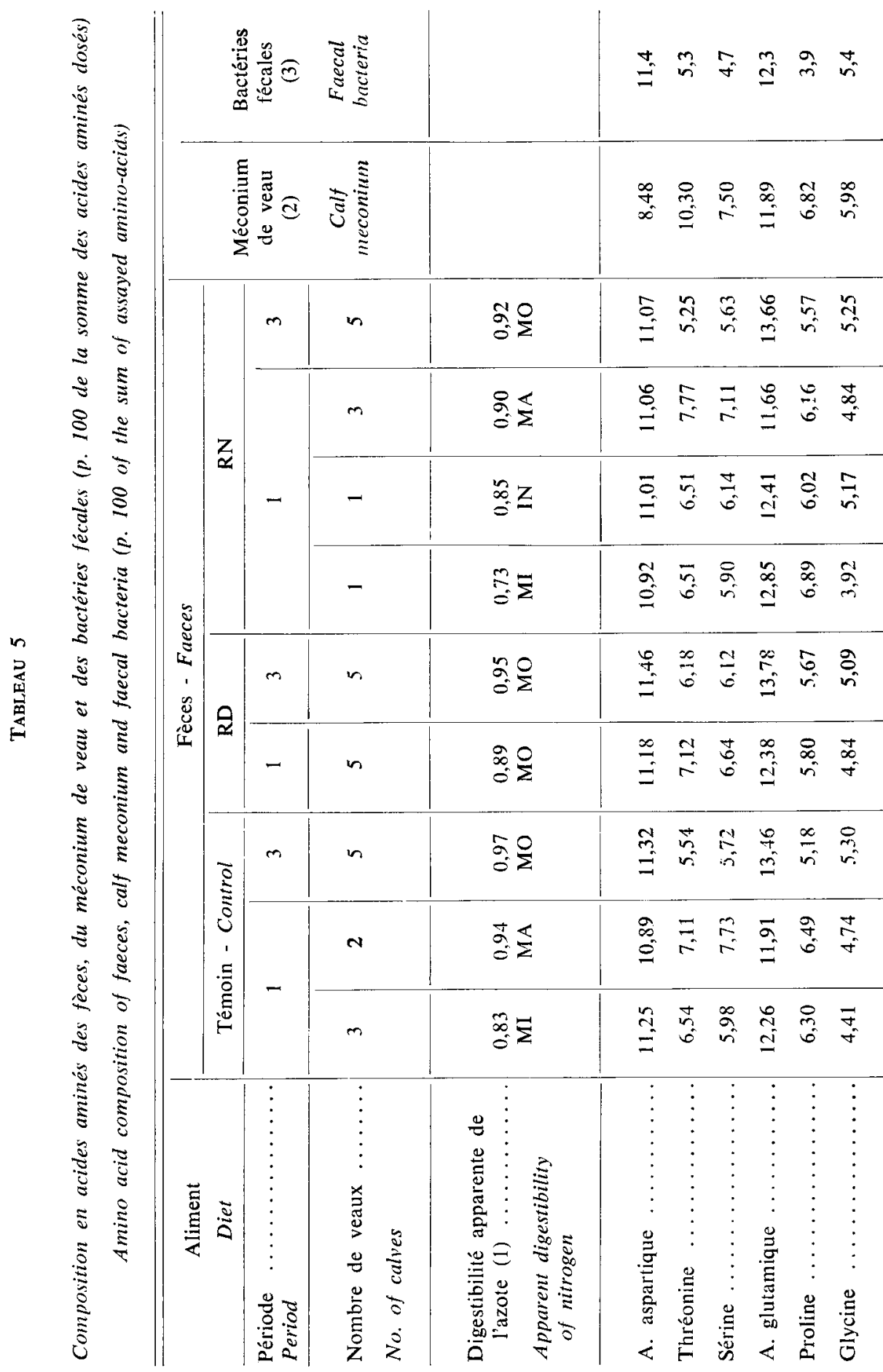




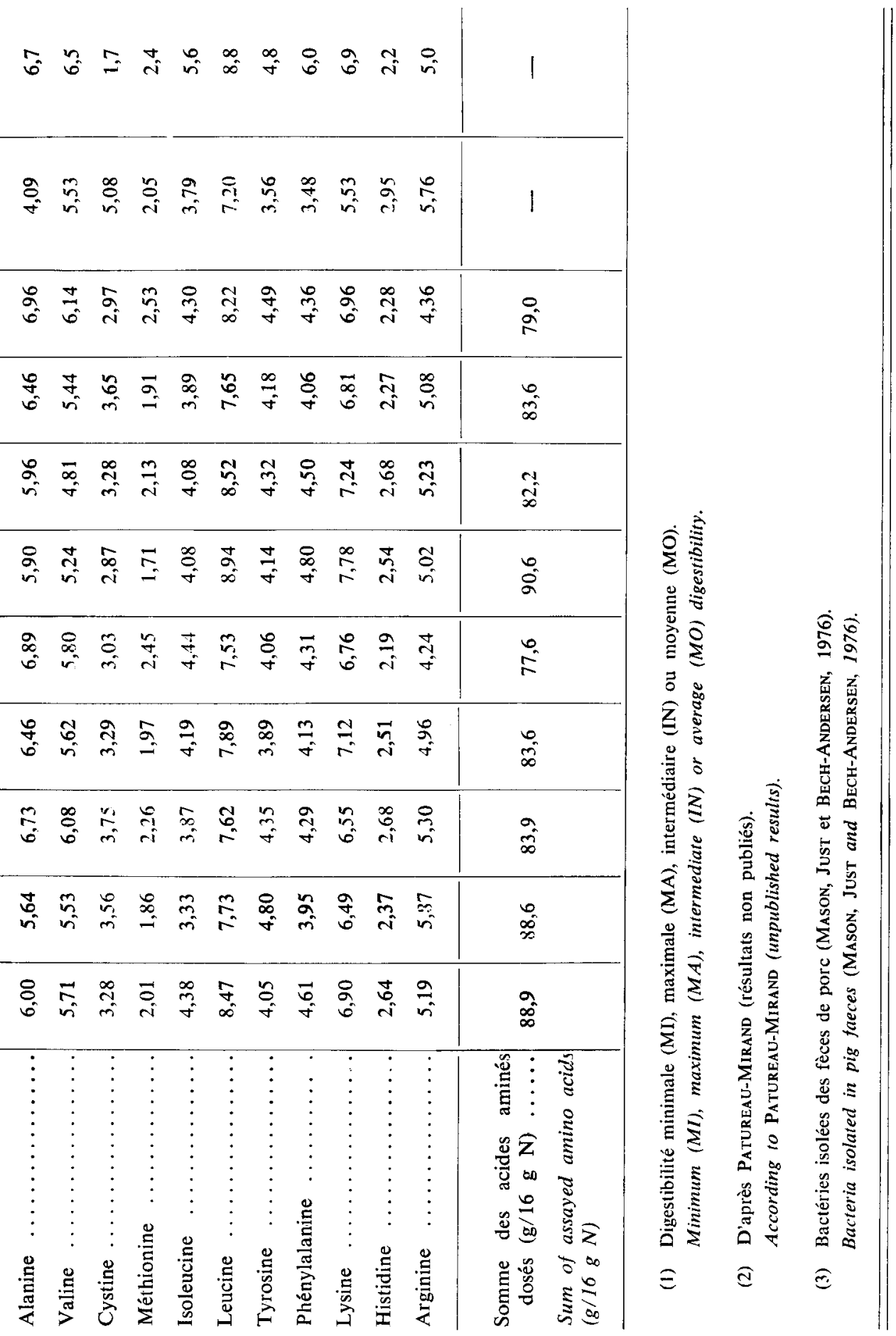




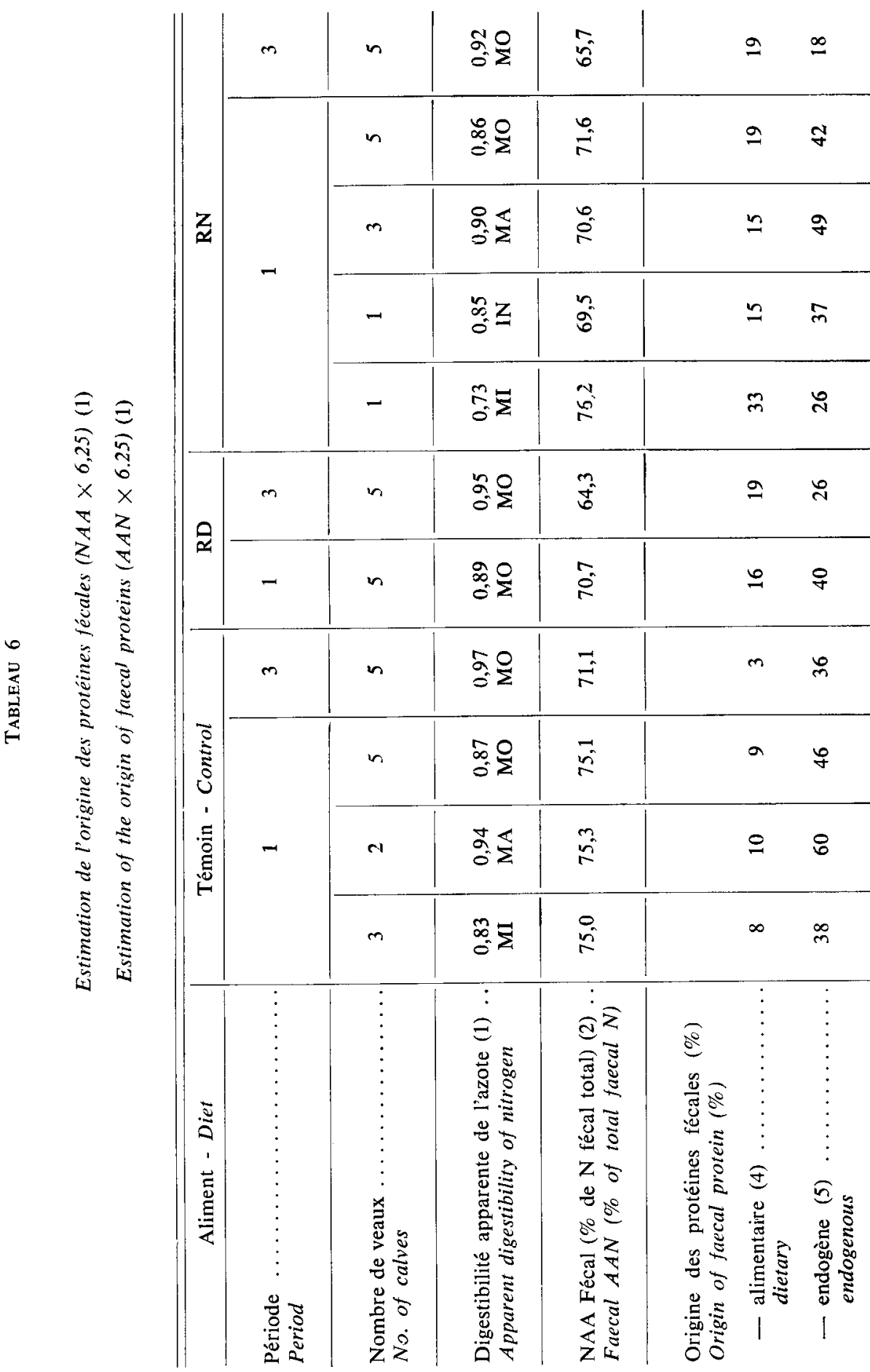




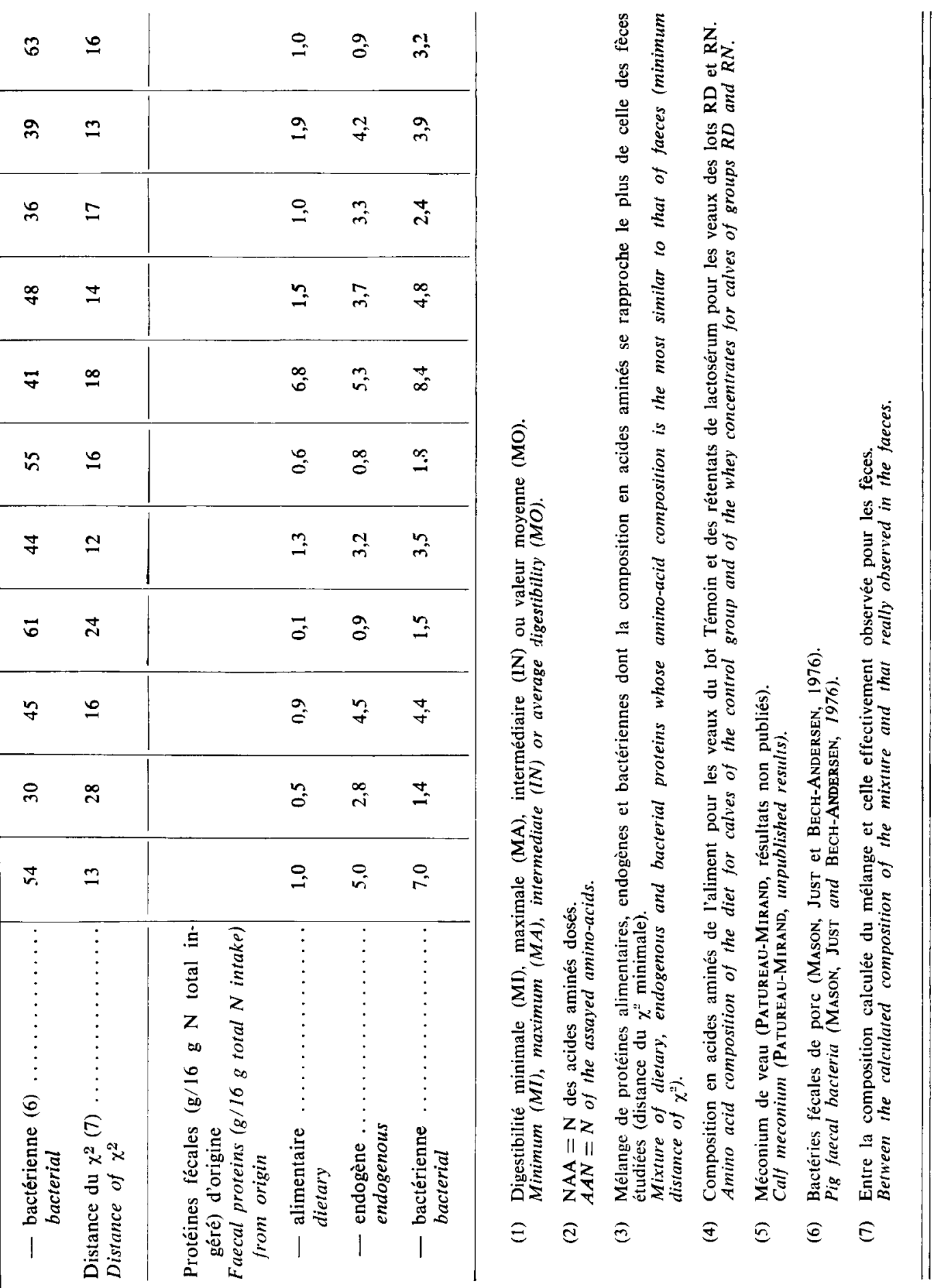


128 au lieu de 45 à 65). La composition des fèces de la période 1 se rapproche d'autant plus de celle du méconium de veau que la digestibilité de l'azote est élevée ; inversement, elle s'éloigne de la composition en acides aminés des protéines ingérées (surtout avec le régime $\mathrm{RN}$ ) et de celle des bactéries fécales (surtout avec le régime Témoin). Ainsi, avec le régime $\mathrm{RN}$, les distances du $\chi^{2}$ entre la composition des fèces et celles du méconium ou du rétentat $R N$ sont respectivement de 126 ou 106 quand la digestibilité est minimum et de 68 ou 161 quand elle est maximum; avec le régime Témoin, la distance du $\chi^{2}$ par rapport aux bactéries fécales passe alors de 69 à 128.

\section{Utilisation métabolique des aliments}

\section{- Rétention de l'azote, du calcium et du phosphore (fig. 2)}

Le coefficient de rétention (C.R.) apparente de l'azote et celui du phosphore baissent de la première à la seconde période (significativement pour l'ensemble des régimes) mais évoluent peu ensuite; aucune différence significative n’est observée entre les régimes. Le C.R. apparent du calcium n'évolue pas significativement avec lâge ; pour l'ensemble de l'essai, il est cependant significativement plus élevé avec les aliments Témoin et RD qu'avec l'aliment RN.

Les coefficients d'utilisation pratique (C.U.P.) de lazote, du calcium et du phosphore diminuent de la période 1 à la période 2 et augmentent ensuite, mais cette évolution n'est significative que pour le phosphore (période $1>$ périodes 2 et 3 ). Pour l'ensemble de l'essai, le régime n'a aucun effet significatif sur les C.U.P.; cependant, le C.U.P. du calcium est significativement plus élevé en période 3 avec les aliments Témoin et RD qu'avec l'aliment RN. Les quantités moyennes retenues par $\mathrm{kg}$ de gain de poids vif sont très voisines avec les aliments Témoin, RD et RN $(31,4-32,5$ et $32,1 \mathrm{~g}$ d'azote, $13,8-12,5$ et $12,0 \mathrm{~g}$ de calcium et $8,6-8,2$ et $8,6 \mathrm{~g}$ de phosphore).

\section{- Amino-acidémie (tabl. 7)}

La somme des teneurs en acides aminés libres du sang est toujours très élevée. Elle diminue légèrement quand l'âge augmente chez les veaux du lot Témoin; l'évolution inverse est observée chez les veaux du lot RD mais aucun changement n̈intervient chez les veaux du lot $\mathrm{RN}$. Quel que soit le régime, les concentrations sanguines en thréonine et ornithine augmentent avec l'âge; il en est de même pour l'isoleucine, la lysine, larginine, la citrulline et la tyrosine avec les aliments RD et RN et pour la méthionine et la glycine avec l'aliment Témoin. En revanche, les teneurs en asparagine, acide glutamique et alanine baissent avec les 3 aliments de la période 1 à la période 2, ainsi que les teneurs en valine, leucine, phénylalanine, histidine, glutamine et proline avec l'aliment Témoin.

Avec l'aliment Témoin, les teneurs en méthionine, tyrosine, acide aspartique, citrulline et ornithine sont toujours plus élevées et celles en thréonine, sérine, glutamine et alanine toujours plus faibles quavec les aliments RD et RN. Avec l'aliment RD, les teneurs en valine, méthionine, acide glutamique, proline et alanine, sont un peu plus élevées qu'avec l'aliment $\mathrm{RN}$, surtout en période 2 . 


\section{TABLEAU 7}

Teneurs en acides aminés libres du sang ( $\mathrm{mg} / 100 \mathrm{ml}$ de sang) Blood free amino-acids $(\mathrm{mg} / 100 \mathrm{ml}$ of blood)

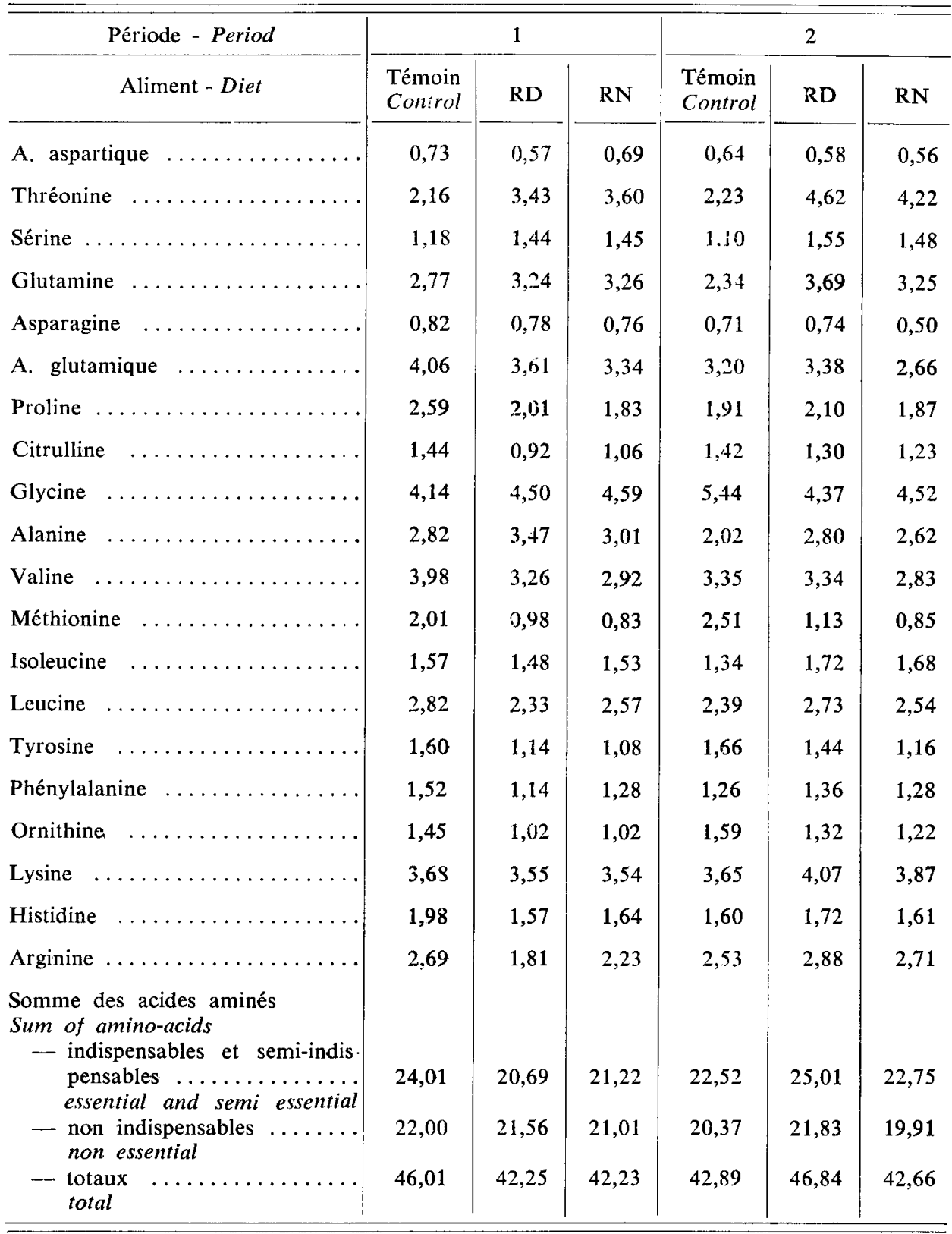




\section{4. - Discussion}

L'augmentation observée avec l'âge dans la digestibilité de l'azote et des lipides des aliments s’accorde avec les résultats de nombreux auteurs rappelés dans l'introduction. Elle s'accompagne d'une diminution de la fréquence des états diarrhéiques. L'aptitude du veau à digérer les aliments n'atteint donc son maximum et ne devient régulière qu'à partir de l'âge d'environ un mois. Cela est à relier à l'augmentation importante de certaines sécrétions digestives, notamment de celles d'enzymes protéolytiques pancréatiques au cours du premier mois (Ternouth \& RoY, 1973). Il est cependant possible qu'elle soit également due en partie au développement des fermentations microbiennes dans le caecum et le colon.

La digestibilité calculée des protéines du rétentat $R N$ est voisine de celle des protéines du lait en période $1(0,85$ au lieu de 0,87$)$ mais lui est nettement inférieure en périodes $2(0,80$ au lieu de 0,94$)$ et $3(0,89$ au lieu de 0,97$)$. Une dénaturation relativement modérée des protéines du lactosérum permet d’accroître leur digestibilité et de la rendre très proche de celle des protéines du lait $(0,90-0,87$ et 0,94 respectivement en périodes 1,2 et 3 ), bien que leur évacuation gastrique demeure vraisemblablement beaucoup plus rapide (Toullec, Thivend \& Mathieu, 1971 ; Guilloteau \& Toullec, 1978). Les valeurs obtenues en périodes 2 et 3 pour la digestibilité calculée de l'azote du RD sont très voisines de celles que nous avons déjà observées aux mêmes âges $(0,87$ et 0,94$)$ avec un aliment dont les protéines étaient apportées en totalité par un autre rétentat de lactosérum séché selon le procédé Spray (Toullec et al., 1974). En revanche, la digestibilité des protéines du RD est plus élevée que celle des protéines du lactosérum précipitées par chauffage en présence d'acide chlorhydrique puis séchées par le procédé Hatmaker $(0,66$ et 0,91 respectivement à 3 et 5 semaines, d’après Toullec, Mathieu \& Pion, 1974).

Pour tenter d'apprécier l'origine des protéines apparemment non digérées, il est possible de calculer le mélange de protéines alimentaires, endogènes et bactériennes dont la composition se rapproche le plus de celle effectivement observée pour les fèces (tabl. 6). Le modèle proposé paraît satisfaisant puisque la distance du $\chi^{2}$ entre la composition calculée et celle qui a été mesurée dans les fèces reste faible (inférieure ou égale à 28). L'examen de ce tableau indique que la part des protéines endogènes dans les protéines fécales diminue de la période 1 à la période 3 , au profit des protéines bactériennes qui deviennent alors prépondérantes. Une évolution analogue avec l'âge a été observée avec des protéines de soja et de féverole fermentés (Toullec et al., 1980). Cependant, cela ne signifie pas que la quantité de protéines bactériennes éliminées au niveau des fèces pour $16 \mathrm{~g}$ d'azote ingéré augmente avec l'âge ; c'est même le contraire qui se produit, sauf lorsque la digestibilité apparente de l'azote est presque aussi élevée en période 1 qu'en période 3 . La proportion de protéines alimentaires dans les protéines fécales reste stable avec les aliments RD et RN mais semble diminuer avec l'aliment Témoin. Les quantités de protéines alimentaires et endogènes éliminées pour $16 \mathrm{~g}$ d'azote ingéré sont beaucoup plus faibles en période 3 qu'en période 1 (en moyenne 4,5 et 5,3 fois). L'augmentation de la digestibilité apparente de l'azote avec l'âge correspondrait donc à une amélioration de l'efficacité de la digestion des protéines alimentaires et endogènes.

En période 1, lorsque la digestibilité s'accroît, la part relative des protéines endogènes augmente au détriment de celle des protéines bactériennes (aliment Té- 
moin) ou alimentaires (aliment $\mathrm{RN}$ ) ; néanmoins, les quantités éliminées pour $16 \mathrm{~g}$ d'azote ingéré diminuent dans chacune des 3 catégories de protéines. Les valeurs individuelles les plus élevées pour la digestibilité apparente de l'azote correspondraient donc encore à une meilleure efficacité de la digestion des protéines alimentaires et endogènes; la sécrétion de ces dernières pourrait également être plus faible.

Les quantités de protéines alimentaires éliminées pour $16 \mathrm{~g}$ d'azote ingéré sont en moyenne plus élevées avec les aliments RD et surtout RN qu'avec l'aliment Témoin. La digestibilité réelle des protéines de ce dernier aliment serait donc la plus forte, au moins en période 3 ; en période 1 , il est difficile de conclure car les quantités de protéines microbiennes et endogènes éliminées sont en moyenne plus élevées avec l'aliment Témoin. La dénaturation des protéines du lactosérum permet d'améliorer leur digestibilité réelle puisque les quantités de protéines alimentaires éliminées par voie fécale diminuent, quelle que soit la période. Toutes ces interprétations doivent cependant être consicérées avec prudence. Ainsi, les protéines alimentaires qui échappent à la digestion pourraient avoir une composition assez différente de celle de l'ensemble des protéines ingérées. Dans le cas de l'aliment Témoin, les protéines sériques résistent peut-être davantage que les caséines à l'action des enzymes digestives et à celle des bactéries puisque la composition en acides aminés des protéines fécales est moins éloigrée de celle des rétentats que de celle de l'aliment. En période 1, quand la digestibilité de l'azote de l'aliment Témoin est minimum, la distance du $\chi^{2}$ entre les fèces et l'aliment est de 285 , alors qu'elle n'est que de 130 par rapport au rétentat natif.

Quel que soit le régime, la digestibilité et le C.U.P. du calcium évoluent dans le même sens que le C.U.P. de l'azote (pour l'ensemble des données $r=0,83$ et 0,82 $\mathrm{p}<0,01$ ). La rétention du calcium est donc fortement liée à celle de l'azote, comme l'ont observé RAVEN \& RoBINSON (1960). Les quantités de calcium excrété par voie urinaire sont généralement très faibles, ce qui confirme les résultats de GuEguEN \& Mathieu (1962) montrant que chez le veau préruminant, la régulation de la rétention du calcium se fait presque exclusivement au niveau intestinal. La rétention du phosphore est également fortement liée à celles de l'azote et du calcium $(r=0,71$ et $0,82-p<0,01$, entre C.U.P. P, d'une part et C.U.P. $\mathbf{N}$ et $\mathrm{Ca}$, d'autre part). La digestibilité du phosphore est influencée par celle du calcium $(r=0,90-p<0,01)$. La régulation de sa rétention a cependant principalement lieu au niveau urinaire, comme l'ont indiqué GUEGUEN \& MATHIEU (1962), puisque les quantités ainsi éliminées sont beaucoup plus élevées et plus variables que celles de calcium. Les faibles écarts observés entre les régimes en ce qui concerne l'utilisation du calcium et du phosphore, semblent donc dus aux différences qu'ils entraînent dans l'utilisation de l'azote. La forme du calcium et du phosphore pourrait également avoir une influence sur leur digestibilité. En effet, la part de ces minéraux apportée par du phosphate bicalcique est 2 fois plus forte dans les aliments RD et RN que dans l'aliment Témoin (tabl. 3).

Les teneurs sanguines en acides aminés libres sont très élevées, compte tenu de l'âge et du niveau d'ingestion. Ainsi, la somme des teneurs en acides aminés libres est environ 1,6 fois pl élevée que celle observée par Patureau-Mirand \& Troccon (résultats non publiés), chez des génisses de 2 ou 4 semaines, recevant en un seul repas par jour, $51 \mathrm{cu} 55 \mathrm{~g}$ de matière sèche d'un aliment d'allaitement dont la composition était très voisine de celle de notre aliment Témoin. Cela indique que l'utilisation métabolique des acides aminés est limitée, probablement par un déficit énergétique par rapport aux protéines, étant donné la digestibilité peu élevée des 
3 aliments au cours des périodes 1 et 2 . Les différences observées entre les animaux recevant le régime Témoin et les autres veaux dans les teneurs sanguines en thréonine, méthionine et alanine correspondent aux écarts dans les teneurs alimentaires (tabl. 2). Le rapport de la concentration en tyrosine à celle en phénylalanine est plus faible dans le sang des veaux des lots RD et surtout RN que dans celui des animaux du lot Témoin, ce qui témoigne d'un apport insuffisant de ces 2 acides aminés avec les régimes $\mathrm{RD}$ et $\mathrm{RN}$ par rapport aux autres acides aminés indispensables et semiindispensables (Patureau-Mirand et al., 1974). Les très faibles différences observées dans les teneurs sanguines en lysine libre entre ces 2 derniers régimes indiquent que le traitement thermique supplémentaire appliqué au rétentat RD n'a pas d'effet nocif sur la disponibilité de cet acide aminé, bien qu’il soit le plus sensible à la réaction de Maillard (Adrian, 1972 ; van den Breuel, Jenneskens \& Mol., 1972 ; ERBERSDOBLER, 1979).

L'amélioration observée en appliquant un traitement thermique supplémentaire au rétentat $\mathrm{RD}$ est en contradiction avec les résultats obtenus par certains auteurs, en soumettant du lait écrémé à un degré de chauffage analogue. Ce traitement entraîne une baisse de la digestibilité de lazote au cours de la première semaine de vie du veau (Shillam \& RoY, 1963), une augmentation de la mortalité et une diminution de la croissance (ShIllam, RoY \& INGRAM, 1962), des quantités d'acide chlorhydrique et de protéases sécrétés par la caillette et le pancréas (TERNouTh \& Roy, 1973 ; Williams, Roy \& Gillies, 1976), ainsi que de la proportion de protéines hydrolysées dans la caillette (TAGari \& RoY, 1969). En revanche, LisTer \& EMmons (1976) obtiennent des résultats aussi satisfaisants en ce qui concerne la fréquence des diarrhées, la croissance et la digestibilité de l'azote en comparant 2 températures $\left(74\right.$ et $60^{\circ} \mathrm{C}$ ) appliquées pendant $30 \mathrm{mn}$; une température plus élevée $\left(85^{\circ} \mathrm{C}\right)$ entraine une détérioration des 2 premiers paramètres.

En conclusion, lutilisation digestive des protéines du lait et du lactosérum augmente de la naissance à la cinquième semaine d’âge, chez le veau préruminant. Les protéines du lactosérum sont un peu moins bien utilisées que celles du lait durant cette période, mais leur dénaturation partielle par voie thermique permet d'en améliorer la digestibilité réelle. Les traitements thermiques modérés peuvent donc accroître la valeur nutritionnelle de certains produits laitiers.

Accepté pour publication en juillet 1981.

\section{Remerciements}

A la Délégation Générale à la Recherche Scientifique et Teghnique pour l'aide financière apportée à la réalisation de ce travail.

A la Société des Fromageries BEL, 6, avenue de Penthere, e, 75008 Paris, qui a préparé les rétentats de lactosérum. 


\section{Summary \\ Utilization of milk and whey proteins by the young pre-ruminant calf. Influence of age and of whey protein denaturation}

Three milk replacers (control, RD and RN) were prepared (tables 2 and 3). In the control milk replacer proteins were totally provided by skim milk powder supplemented with methionine; in RD and RN, 58 p. 100 of proteins were supplied by a concentrate of denaturated (RD) or native whey (RN), the rest by skim milk powder. Both concentrates (tables 1 and 2 ) were pasteurized $\left(72^{\circ} \mathrm{C}\right.$ a few seconds) then concentrated and spraydried. Denaturation of RD was obtained by a supplementary heating $\left(75^{\circ} \mathrm{C}, 30 \mathrm{~min}\right.$.) after concentration which increased the percentage of denaturated proteins from 8 to 34 .

Each diet was offered to 5 Holstein $x$ Friesian male calves from the first day of age. Digestibility was measured from 3 to 8 days of age (P1) from 14 to 19 days of age (P2) and from 28 to 33 days of age (P3). The apparent digestibility of the control diet increased regularly from $\mathrm{P} 1$ to $\mathrm{P} 3$; thus for protein it rose from 0,871 to 0.935 and 0.966 (fig. 1 and 2). That of the other two diets only increased between P2 and P3 changing for protein from 0.888 to 0.896 and 0.950 (RD) and from 0.859 to 0.854 and 0.923 (RN). The individual variations were larger during $\mathrm{P} 1$ and $\mathrm{P} 2$ than during P3. The increase observed between P2 and P3 was significant for every diet. Protein digestibility was significantly higher with the control diet than with RN diet during P3.

Analysis of the amino acid composition of the facces (tables 5 and 7) showed that increase with age in the apparent digestibility of protein was probably due to an improvement in the digestion of dietary and endogenous proteins. This seems also to be the case for P1 accounting for the higher true digestibilities observed in some calves. The true digestibility of the proteins of RD and especially $\mathrm{RN}$ diets seems to be lower than that of the milk proteins. The blood levels of free amino acids, especially the lysine content were little affected by denaturation (table 8 ).

Digestive utilization of milk and whey proteins increased from birth to the fifth week of age. Whey proteins were a little less used than that of milk during this period, but their partial denaturation by heat-treatment contributed to improving the true digestibility. Consequently, moderate heat treatments may increase the nutritional value of some dairy pioducts.

\section{Références bibliographiques}

Adrian J., 1972. La réaction de Maillard vue sous l'angle nutritionnel. I. Domaine de la réaction de Maillard. Indust. Alim. Agr., 89, 1281-1289.

Bell J.M., Royan G.F., Youngs C.G., 1974. Digestibility of pea protein concentrate and enzyme-treated pea flour in milk replacers for calves. Can. J. Anim. Sci., 54, 355-362.

BlAXTER K.L., Wood W.A., 1953. Some observations on the biochemical and the physiological events associated with diarrhoea in calves. Vet. Rec., 65, 889-892.

Bouchard R., Brisson G.J., Julien J.P., 1973. Nutritive value of bacterial sludge and whey powders for protein in calf milk replacers and on chromic oxide as indicators of digestibility. J. Dairy Sci., 56, 1445-1449.

Breuel (Van Den) A.M.R., Jenneskens P.J., Mol J.J., 1972. Availability of lysine in skim milk powders processed under various conditions. Neth. Milk Dairy J., 26, 19-30.

ERBERSDOBLER H.F., 1979. Proteinqualitätsuntersuchungen and der Jahresproduction von Magermilchpulver eines Trockenmilchwerkes. 2. Lysinschädigung bei der Milchtrocknung. Milchwissenschaft, 34, 325-328.

Gueguen L., Mathieu C.-M., 1962. L'utilisation des éléments minéraux de la ration par le veau. II. Influence du régime alimentaire. Ann. Zootech., 11, 115-134. 
Guilloteau P., Patureau-Mirand P., Toullec R., Prugnaud J., 1980. Digestion of milk protein and methanol-grown bacteria protein in the preruminant calf. II. Amino acid composition of ileal digesta and faeces and blood levels of free amino acids. Reprod. Nutr. Develop., 20, 615-629.

Guilloteau P., Toullec R., 1978. Digestion des protéines du lactosérum dans la caillette du veau préruminant. $X X^{c}$ Congrès Intern. Laiterie, 942, Synaps, Neuilly.

Huber J.T., Jacobson N.L., Allen R.S., Hartman P.A., 1961. Digestive enzyme activities in the young calf. J. Dairy Sci., 44, 1494-1501.

Lister E.E., Emmons D.B., 1976. Quality of protein in milk replacers for young calves. II. Effect of heat treatment of skim milk powder and fat levels on calf growth, feed intake and nitrogen balance. Can. J. Anim. Sci., 56, 327-333.

MASON V.C., Just A., Bech-ANDERSEN S., 1976. Bacterial activity in the hind-gut of pigs. 2. Its influence on the apparent digestibility of nitrogen and amino-acids. Z. Tierphysiol. Tierernähr. Futtermittelk., 36, 310-324.

Nishimatsu I., Kumeno F., 1966. Nutrition of young dairy calves. 3. Utilization of soybean protein. Jap. J. Zootech. Sci., 37, 25-31.

Paruelle J.L., Toullec R., Frantzen J.F., Mathieu C.-M., 1972. Utilisation des protéines par le veau préruminant à l'engrais. I. Utilisation digestive des protéines du soja et des levures d'alcanes incorporées dans les aliments d'allaitement. Ann. Zootech., 21, 318-331.

Paruelle J.L., Toullec R., Mathieu C.-M., 1973. Utilisation digestive d'aliments d'allaitement contenant des lactosérums de différentes qualités par le veau préruminant d l'engrais. Ann. Zootech., 22, 237-242.

Patukeau-Mirand P., Toullec: R., Guilloteau P., Pion R., 1977. Influence de la nature des protéines alimentaires sur la composition en acides aminés des fèces du veau préruminant. Ann. Biol. anim. Bioch. Biophys., 17, 71-83.

Patureau-Mirand P., Toullec R., Paruelle J.L., Prugnaud J., Pion R., 1974. Influence de la nature des matières azotées des aliments d'allaitement sur l'aminoacidémie du veau préruminant. I. Matières azotées du lait, du lactosérum, du poisson et des levures d'alcanes. Ann. Zootech., 23, 343-358.

Prugnaud J., Pion R., 1976. Dosage des acides aminés dans les aliments. Journées de Biochimie Beckman, Nantes.

Raven A.M., Robinson K.L., 1960. Studies of the nutrition of the young calf. 3. A comparison of unhydrogenated palm-kernel oil, hydrogenated palm-kernel oil, and butterfat, as constituents of a milk diet. Brit. J. Nutr., 14, 135-146.

Shillam K.W.G., Roy J.H.B., 1963. The effect of heat treatment on the nutritive value of milk for the young calf. 5. A comparison of spray dried skim milks with different pre-heating treatments and roller dried skim-milk, and the effect of chlortetracycline supplementation of the spray-dried skim-milks. Brit. J. Nutr., 17, 171-181.

Shillam K.W.G., RoY J.H.B., Ingram P.L., 1962. The effect of heat treatment on the nutritive value of milk for the young calf. 3 . The effect of the pre-heating treatment of spray-dried skim milk and a study of the effect of ultra-high temperature treatment of separated milk. Brit. J. Nutr., 16, 585-591.

Snedecor G.W., Cochran W.G., 1971. Méthodes statistiques, 287-306. Association de Coordination technique agricole, Paris.

Stewart J.A., Muller L.L., Griffin A.T., 1974. Use of whey solids in calf feeding. Austr. J. Dairy Technol., 29, 53-58.

Sтово I.J.F., RoY J.H.B., 1977. The use of microbial protein in milk substitutes diets for calves. Anim. Prod., 24, 143 (Abstr.).

TAgari H., Roy J.H.B., 1969. The effect of heat treatment on the nutritive value of milk for the young calf. 8. The effect of pre-heating treatment of spray-dried skim milk on the $\mathrm{pH}$ and the contents of total protein and non-protein nitrogen of the pyloric outflow. Brit. J. Nutr., 23, 763-782.

Ternouth J.H., Roy J.H.B., 1973. The effect of diet and feeding technique on digestive function in the calf. Ann. Rech. Vét., 4, 19-30. 
Toullec R., Coroller J.Y., Patureau-Mirand P., Melcion J.P., Prugnaud J.P., Valdebouze P., Delort-Laval J., Cerning J., 1980. Influence des traitements technologiques sur l'utilisation des protéines de la féverole par le veau préruminant. Ann. Zootech., 29, 339-361.

Toullec R., Frantzen J.F., Mathieu C.-M., 1974. Influence de la coagulation des protéines du lait sur l'utilisation digestive d'un lait de remplacement par le veau préruminant. Ann. Zootech., 23, 359-364.

Toullec R., Frantzen J.F., Maubois J.-L., Pion R., 1974. Utilisation digestive par le veau préruminant des protéines du lactosérum traitées par ultrafiltration sur membrane. La Technique Laitière, 828, 17-21.

Toullec R., Mathieu C.-M., Pion R., 1974. Utilisation des protéines du lactosérum par le veau préruminant à l'engrais. II. Digestibilité et utilisation pour la croissance. Ann. Zootech., 23, 75-87.

Toullfy. R., Mathiev C.-M., Vassal L., Pion R., 1969. Utilisation digestive des protéines du lactosérum par le veau préruminant à l'engrais. Ann. Biol. anim. Bioch. Biophys., s, $661-664$.

Toullec R., Thivend P., Mathieu C.-M., 1971. Utilisation des protéines par le veau préruminant à l'engrais. I. Vidange stomacale comparée du lait entier et de deux laits de remplacement ne contenant que des protéines de lactosérum comme source de matières azotées. Ann. Biol. anim. Bioch. Biophys., 11, 435-453.

Tourneur C., Lenoir J., 1980. Sensibilité in vitro des protéines du lactosérum à l'hydrolyse enzymatique. Ann. Nutr. Alim., 34, 42-43.

Williams V.J., Roy J.H.B., Gillies C.M., 1976. Milk substitute diet composition and abomasal secretion in the calf. Brit. J. Nutr., 36, 317-335. 